\title{
Remote sensing for predicting potential habitats of Oncomelania hupensis in Hongze, Baima and Gaoyou lakes in Jiangsu province, China
}

\author{
Guo-Jing Yang, ${ }^{1,2}$, Penelope Vounatsou², Marcel Tanner ${ }^{2}$, Xiao-Nong Zhou ${ }^{3}$, \\ Jürg Utzinger ${ }^{2}$
}

${ }^{1}$ Jiangsu Institute of Parasitic Diseases, Wuxi 214064, People's Republic of China; ${ }^{2}$ Department of Public Health and Epidemiology, Swiss Tropical Institute, Basel, Switzerland; ${ }^{3}$ National Institute of Parasitic Diseases, Chinese Center for Disease Control and Prevention, Shanghai 200025, People's Republic of China

\begin{abstract}
Political and health sector reforms, along with demographic, environmental and socio-economic transformations in the face of global warming, could cause the re-emergence of schistosomiasis in areas where transmission has been successfully interrupted and its emergence in previously non-endemic areas in China. In the present study, we used geographic information systems and remote sensing techniques to predict potential habitats of Oncomelania hupensis, the intermediate host snail of Schistosoma japonicum. Focussing on the Hongze, Baima and Gaoyou lakes in Jiangsu province in eastern China, we developed a model using the normalized difference vegetation index, a tasseled-cap transformed wetness index, and flooding areas to predict snail habitats at a small scale. Data were extracted from two Landsat images, one taken during a typical dry year and the other obtained three years later during a flooding event. An area of approximately $163.6 \mathrm{~km}^{2}$ was predicted as potential O. hupensis habitats around the three lakes, which accounts for $4.3 \%$ of the estimated snail habitats in China. In turn, these predicted snail habitats are risk areas for transmission of schistosomiasis, and hence illustrate the scale of the possible impact of climate change and other ecological transformations. The generated risk map can be used by health policy makers to guide mitigation policies targetting the possible spread of O. hupensis, and with the aim of containing the transmission of S. japonicum.
\end{abstract}

Keywords: schistosomiasis, Schistosoma japonicum, Oncomelania hupensis, snail habitats, remote sensing, geographic information system, risk mapping and prediction, China.

\section{Introduction}

Schistosomiasis japonica is endemic in China and must have been perceived as a public health problem there in ancient times (Jordan, 2000). The historical evidence stems from the recovery of Schistosoma japonicum eggs from the liver and rectum of a well-preserved female corpse from the Western Han Dynasty (206 B.C. - 24 A.D.) (Mao and Shao, 1982; Zhou et al., 2005). However, it

Corresponding author:

Penelope Vounatsou

Department of Public Health and Epidemiology

Swiss Tropical Institute, P. O. Box, CH - 4002 Basel, Switzerland

Tel. +4161 2848109; Fax: +41612848105

E-mail: penelope.vounatsou@unibas.ch was only in 1905 that S. japonicum was first described in the literature, with parasite eggs identified in an 18-year-old Chinese male with dysentery (Logan, 1905). Once it became clear that the disease caused substantial social and economic hardship (Mao, 1948; Maegraith, 1958; Chen and Feng, 1999), a national control programme was initiated, shortly after the establishment of the People's Republic of China in 1949. Dedicated control activities over the past 50 years have reduced the prevalence of human infections with $S$. japonicum by more than 90\% (Utzinger et al., 2005; Zhou et al., 2005). However in 2003, an estimated 850,000 people were still infected with an estimated $S$. japonicum with an estimated 65 million people at risk (Zhou et al., 2005). There is considerable 
concern that schistosomiasis might re-emerge, as active transmission has been reported from areas that had previously reached transmission interruption or transmission control (Liang et al., 2006). Underlying reasons include political and health sector reforms, demographic, environmental and socioeconomic changes, and global warming (Bian et al., 2004; Zhou et al., 2004, 2005; Utzinger et al., 2005).

Oncomelania hupensis is the only intermediate host snail of S. japonicum. In 2003, it was estimated that $3,787 \mathrm{~km}^{2}$ of land were infested with $O$. hupensis, particularly in the marshlands surrounding the great lakes in southern China and the Yangtze River basin (Zhou et al., 2005). The two largest lakes in the middle reaches of the Yangtze River are the Dongting Lake and Poyang Lake (Ross et al., 2001; Guo et al., 2005; Zhou et al., 2005). It has been speculated that some non-endemic marshlands in the north of these lakes could become colonized by $O$. hupensis due to climate change and other ecological transformations (Yang et al., 2005a). For example, Hongze, Baima and Gaoyou lakes, situated north of the Yangtze River basin in the transition zone between warm temperate and sub-tropical climate zones, are potential risk areas for schistosomiasis. Snails might colonize the nonendemic Hongze and Baima lakes, and might reemerge in Gaoyou Lake from where they were eliminated many years ago.

In one of our previous studies we documented that the average January temperature in China increased considerably over the past 30 years (Yang et al., 2005a). Since Hongze and Baima lakes are both in the predicted at-risk area of colonization with O. hupensis, there is concern that schistosomiasis might become a public health problem there. Implementation of the South-to-North water transfer project, the second largest water-resource development project in China (http://www.nsbd. mwr.gov.cn/), could result in a wider distribution of snails by enlarging the wetlands and enabling direct snail transfers from the infested Yangtze River to Gaoyou, Baima and Hongze lakes.

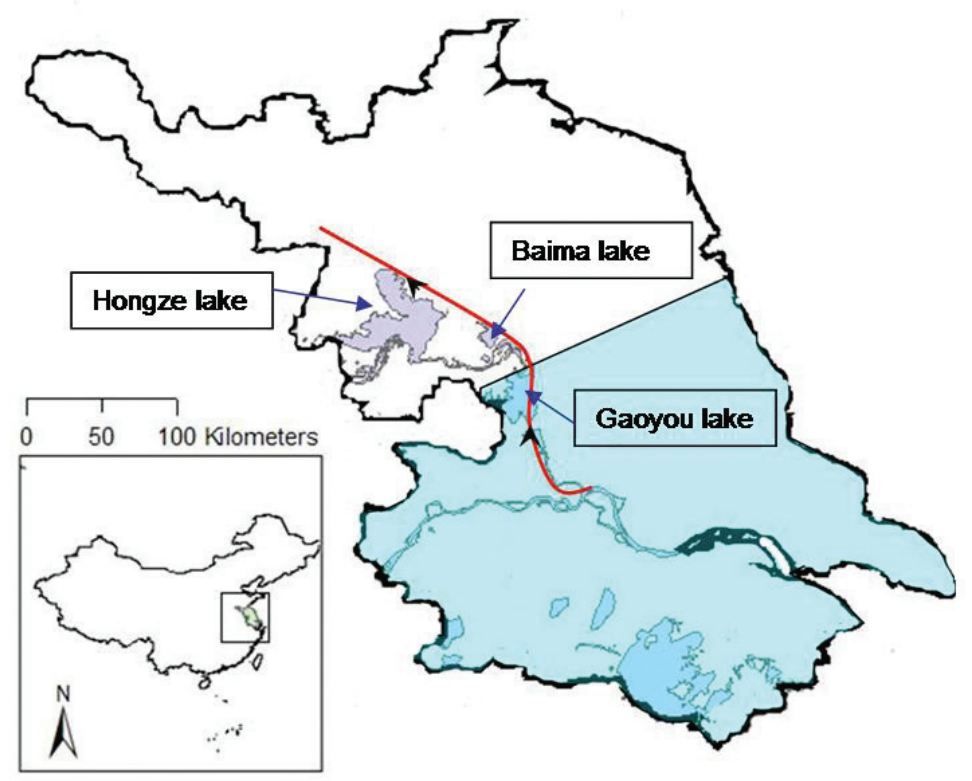

Fig. 1. Study area in central Jiangsu province including South-to-North water transfer project. The shaded region indicates the current schistosome-endemic area. Red line delineates the main route of the South-to-North water transfer project, with arrows indicating the direction of water-flow. 
In the study presented here, we used geographic information system (GIS), remote sensing techniques and a modelling approach to predict the potential habitats of O. hupensis around Hongze, Baima and Gaoyou lakes. Remotely-sensed environmental data included a surrogate vegetation index, the Tasseled-cap transformed wetness index, and information about flooding to predict snail habitats at a small scale.

\section{Materials and methods}

\section{Study area and satellite imagery}

The study area is located in central Jiangsu province, eastern China, and focuses on three lakes, namely Gaoyou, Baima and Hongze (Fig. 1). Also depicted on this figure is the main route of the South-to-North water transfer project, with arrows indicating the direction of water-flow.

Two Landsat TM images were purchased from China Remote Sensing Ground Station (Beijing, China). The first image was taken on 16 September 2000 , representing a typical dry year. The second image was obtained on 19 October 2003, which coincided with a flooding event. The images covered the regions stretching from $32^{\circ} 5^{\prime} \mathrm{N}$ to $34^{\circ} 4^{\prime} \mathrm{N}$ latitude and from $118^{\circ} 4^{\prime} \mathrm{E}$ to $119^{\circ} 7^{\prime} \mathrm{E}$ longitude. The spatial resolution of each image is about $30 \times 30 \mathrm{~m}$.

Satellite imagery analyses were performed in ENVI version 4.0 software (Boulder, CO, USA) and the following procedures were carried out: (i) georeferencing, (ii) classification for presence of water or land, (iii) extraction of the normalized difference vegetation index (NDVI) and the Tasseled-cap transformed wetness index. The results were then validated by ground truthing with historical snail data in a part of the study area.

\section{Georeferencing}

The two images were georeferenced by attributing 20-30 readily distinguishable and known coordinate locations in the reference layer to the images (e.g. road crossings and banks of water bodies). Following the georeferencing process, the coordinate system of the two images was adjusted to WGS_1984_UTM_Zone_50N.

\section{Image classification}

The images were classified by using an unsupervised classification approach (ENVI, 2003), and all sorted image pixels were grouped into seven categories according to their spectral values, by means of a cluster analysis algorithm without any userdefined training classes. Subsequently, the images were sorted into two broad categories, namely (i) water, and (ii) land.

The two classified images were then overlaid by subtraction, and we created a composite image with three classes as detailed in Box 1.

\section{Box 1. Composite image classification}

- Composite_1: water surface identified on both images (dry and wet year)

- Composite_2: regions with water identified during a flooding event and land during the dry year

- Composite_3: land identified on both images (dry and wet year)

In the year 2000 image, both NDVI and the Tasseled-cap transformed wetness index were grouped into three classes as summarized in Box 2 .

\section{Box 2. Dry year image classification}

Normalized difference vegetation index (NDVI)

- NDVI_1: regions with water

- NDVI_2: regions with lowest category (out of three categories) of NDVI value

- NDVI_3: regions with highest category (out of three categories) of NDVI value

Tasseled-cap transformed wetness index

- Wetness_1: regions with water

- Wetness_2: regions with highest category (out of three categories) of soil moisture

- Wetness_3: regions with lowest category (out of three categories) of soil moisture 
The regions classified as NDVI_3, Wetness_2 and Composite_2 were considered as potential snail habitats.

\section{Validation}

Validation of the model prediction was only feasible for the Gaoyou Lake area, where we used ground truth data derived from historical snail records. According to records from the Ministry of Health, O. hupensis habitats had been eliminated in the Gaoyou area in the early 1990s (MOH, 2000). Hongze and Baima lakes are not yet infested with O. hupensis, and hence precluding model validation.

\section{Results}

The predicted O. hupensis habitats around the three lakes are depicted in Fig. 2. The red colour corresponds to intermittently flooded areas covered by grass and where soil moisture is high. A total of 181,789 pixels were predicted as potential O. hupensis habitats, which correspond to a surface of approximately $163.6 \mathrm{~km}^{2}$, given the spatial resolution of the Landsat images used. There were 94,684 pixels or about $85.2 \mathrm{~km}^{2}$ of potential snail habitats around Hongze and Baima lakes, and a total of 87,105 pixels, corresponding to $78.4 \mathrm{~km}^{2}$ of potential snail habitats, around Gaoyou Lake.

The values of the NDVI and the Tasseled-cap transformed wetness index in these predicted snail habitats ranged from 0 to 4.9 and from -41 to -3 , respectively. They are summarized in Table 1, along with ranges put forth by other research groups focussing on prediction of risk areas for O. hupensis in other parts of China.

Validation of our predicted snail habitats in the Gaoyou Lake area, using historical snail survey data, revealed that all former snail habitats around this lake were correctly predicted by our model.

\section{Discussion}

There is little doubt that the unusual warming trend observed over the past 30 years is - at least partially - attributable to human activities, namely the increased greenhouse gas emissions (IPCC,

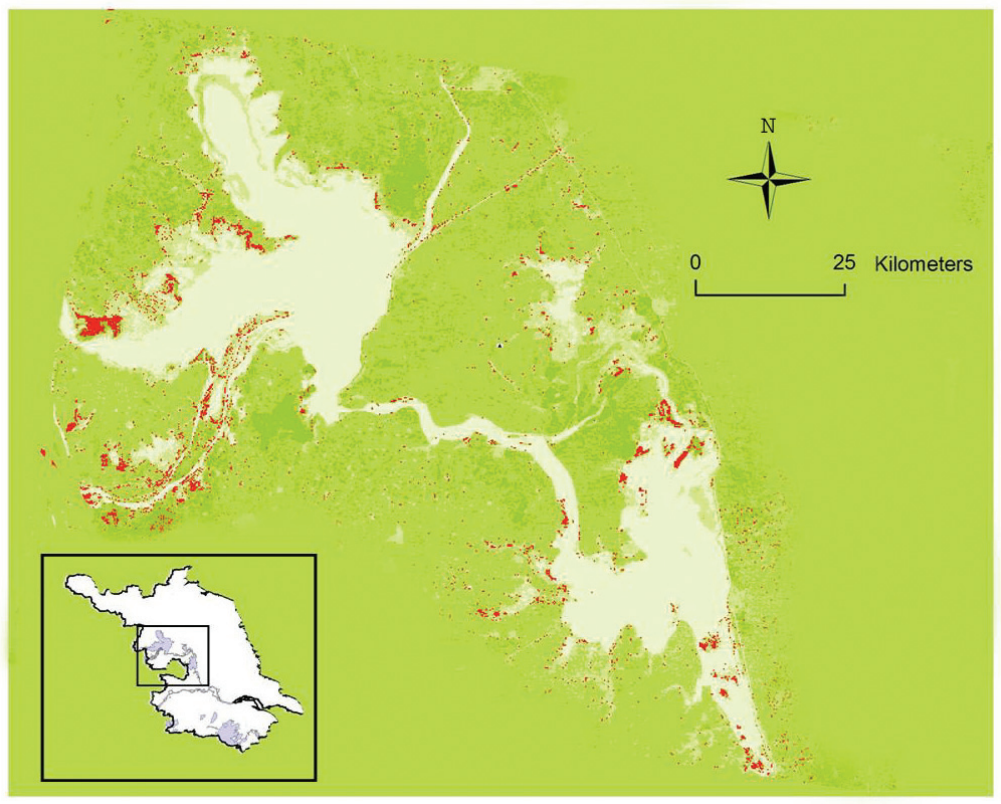

Fig. 2. Potential snail habitats (in red) around Hongze, Baima and Gaoyou lakes in central Jiangsu province, eastern China. 
Table 1. Remotely-sensed environmental features (normalized difference vegetation index, NDVI; second modified soil-adjusted vegetation index, MSAVI2; Tasseled-cap transformed wetness index) derived from satellite images by different research groups for prediction of O. hupensis habitats.

\begin{tabular}{|c|c|c|c|c|c|c|}
\hline \multirow[t]{2}{*}{$\begin{array}{l}\text { Author } \\
\text { (year) }\end{array}$} & \multicolumn{2}{|c|}{$\begin{array}{c}\text { Vegetation index value of } \\
\text { snail habitats }\end{array}$} & \multirow{2}{*}{$\begin{array}{l}\text { Wetness index } \\
\text { value of snail } \\
\text { habitats }\end{array}$} & \multirow[t]{2}{*}{$\begin{array}{l}\text { Image data } \\
\text { transformation }\end{array}$} & \multirow[t]{2}{*}{ Application area } & \multirow[t]{2}{*}{ Image archiving time } \\
\hline & NDVI & MSAVI2 & & & & \\
\hline $\begin{array}{l}\text { Lin et al. } \\
(2002)\end{array}$ & $\begin{array}{l}6 \text { highest classes } \\
\text { out of } 25 \text { classes }\end{array}$ & - & - & Digital number & $\begin{array}{l}\text { Poyang Lake, Jiangxi } \\
\text { province }\end{array}$ & $\begin{array}{l}\text { Flooding: } 25 \text { August, } 1998 \\
\text { Dry season: } 26 \text { April } 1999\end{array}$ \\
\hline \multirow[t]{2}{*}{$\begin{array}{l}\text { Zhou et al. } \\
\text { (2002a) }\end{array}$} & $\begin{array}{l}6 \text { highest classes } \\
\text { out of } 25 \text { classes }\end{array}$ & - & - & Digital number & $\begin{array}{l}\text { Poyang Lake, Jiangxi } \\
\text { province }\end{array}$ & $\begin{array}{l}\text { Flooding: } 25 \text { August } 1998 \\
\text { Dry season: } 4 \text { April } 1999\end{array}$ \\
\hline & $\begin{array}{l}6 \text { highest classes } \\
\text { out of } 15 \text { classes }\end{array}$ & - & - & Digital number & $\begin{array}{l}\text { Lower Yantze River } \\
\text { basin, Jiangsu province }\end{array}$ & $\begin{array}{l}\text { Flooding: } 8 \text { August } 1998 \\
\text { Dry season: } 5 \text { May } 1999\end{array}$ \\
\hline $\begin{array}{l}\text { Guo et al. } \\
(2005)\end{array}$ & 108 to 139 & - & -88 to 48 & Digital number & $\begin{array}{l}\text { Poyang Lake, Jiangxi } \\
\text { province }\end{array}$ & $\begin{array}{l}\text { Wet season: } 25 \text { August } 1998 \\
\text { Dry season: } 16 \text { April } 2000\end{array}$ \\
\hline $\begin{array}{l}\text { Zhang et al. } \\
(2005)\end{array}$ & - & 0.222 to 0.41 & -0.23 to -0.152 & $\begin{array}{l}\text { Atmospheric } \\
\text { correction }\end{array}$ & $\begin{array}{l}\text { Jiangning county, } \\
\text { Jiangsu province }\end{array}$ & 11 November 2000 \\
\hline $\begin{array}{l}\text { Yang et al. } \\
(2006)\end{array}$ & 0 to 4.9 & - & -41 to -3 & Digital number & $\begin{array}{l}\text { Hongze, Baima and } \\
\text { Gaoyou lakes, Jiangsu } \\
\text { province }\end{array}$ & $\begin{array}{l}\text { Dry season: } 16 \text { September } 2000 \\
\text { Flooding: } 19 \text { October } 2003\end{array}$ \\
\hline
\end{tabular}

2001; Murphy et al., 2004; McMichael et al., 2006). The Earth has warmed by approximately $0.6^{\circ} \mathrm{C}$ over the last century according to systematic climate records available since 150 years. The increase in the globally averaged temperature has been particularly pronounced during the last three decades, amounting to $0.5^{\circ} \mathrm{C}$ (IPCC, 2001). New analyses suggest that climate change is responsible for over 150,000 deaths per year and a global burden of approximately five million disability adjusted life years lost annually (Hunter, 2003; WHO, 2003; Sutherst, 2004; Haines et al., 2006). In China, the averaged January temperature increased by $0.96^{\circ} \mathrm{C}$ between the 1960s and the 1990s. In some areas of north-eastern China, the mean January temperature increased by as much as $3.0^{\circ} \mathrm{C}$ (Yang et al., 2005a).

The distribution of $\mathrm{O}$. hupensis is restricted to the southern parts of China. Historical records suggest that this distribution is governed by the mean January temperature; snails only occur where the mean January temperature is higher than $0^{\circ} \mathrm{C}$ (Zhou et al., 2002b). In the face of global warming, the January isotherm belt of $0-1^{\circ} \mathrm{C}$ is shifting north- wards. We have estimated that over the past 30 years it might have shifted $26^{\prime}$ north, corresponding to $40 \mathrm{~km}$ (Yang et al., 2005a). Thus, it is conceivable that new areas will become suitable habitats for O. hupensis, when considering temperature as a key ecological feature. Importantly, both Hongze and Baima lakes are located in this new potential area where snails could proliferate, whereas the mean January temperature in the Gaoyou Lake area provided suitable conditions for snails already before. In view of a large water-resource development project underway, i.e. the South-to-North water transfer project, O. hupensis could spread into this area and (re)colonize.

The distribution of $O$. hupensis, which is an amphibious snail, in areas where January temperatures allow survival are governed by a number of other factors that act at a micro-environmental scale. These factors include annual water fluctuations, dense vegetation cover and high soil moisture (Mao, 1990). The current study used three environmental features which have previously proved useful to identify potential snail habitats, i.e. flooded 
region, NDVI and the Tasseled-cap transformed wetness index. The NDVI quantifies the density of green vegetation. The second modified soil-adjusted vegetation index (MSAVI2) is another means to quantify vegetation density by accounting for the differences in soil background (Qi, 1994). The Tasseled-cap transformation is one of the available methods for enhancing spectral information content of Landsat TM data. One of the bands derived from a Tasseled-cap transformation is wetness, which estimates the interrelationship of soil and canopy moisture (Crist and Cicone, 1984). The Hongze, Baima and Gaoyou lake areas act as flood buffers for the Huai River during the rainy season. The water level fluctuations between the dry and rainy seasons are among the predominant factors determining O. hupensis survival. The existence of grass is another indicator that has been used traditionally for snail surveillance by China's national schistosomiasis control programme.

The successful prediction of potential snail habitats in the lake and marshland regions of China by using GIS and remote sensing techniques has been widely documented (Lin et al., 2002; Zhou et al., 2002a; Guo et al., 2005; Zhang et al., 2005), and was reviewed recently (Yang et al., 2005b). Most of the previous studies used two Landsat images corresponding to wet and dry seasons. The regions where flooding occurred were extracted, usually accompanied by the extraction of vegetation and wetness indices, for subsequent prediction of snail habitats. The different ranges for these environmental features, as obtained by different research groups, are summarized in Table 1. Most studies used the NDVI, or MSAVI2, coupled with a Tasseled-cap transformed wetness index (Crist and Cicone, 1984), as these features are relevant for snail survival (Guo et al., 2005; Zhang et al., 2005). Interestingly, the studies reported slightly different ranges for the vegetation and wetness indices within the predicted snail habitats, depending on the time of the year and the spatial location the images were taken from. In addition, there were slight differences in data processing techniques to obtain the vegetation index and the Tasseled-cap transformed wetness index, which might explain some of the differences in the ranges of these indices. For example, there are two Tasseled-cap transformations applied on TM images, one is based on raw image data or digital number, while the other arises from a reflectance factor analysis. The latter takes into account atmospheric effects. Furthermore, the studies were carried out in different regions with distinct environmental characteristics, which may have influenced the ranges of the vegetation and the wetness indices. Other studies categorised the two indices and assumed that the regions with the highest category were at the highest risk for occurrence of O. hupensis (Lin et al., 2002; Zhou et al., 2002a). Considering the above mentioned points and the fact that limited field data is available for validation, we defined the highest index categories as the high risk areas for snail proliferation in the present study.

In previous work, validation with ground truth data was performed only in those areas where snails were predicted. All models represented high sensitivity, especially when applied at medium- and large-sized areas of marshlands (Lin et al., 2002; Zhou et al., 2002a; Guo et al., 2005; Zhang et al., 2005). However, none of these studies assessed the specificity since the models were not validated for those regions predicted as snail-free. Owing to the absence of ground truth data in two of the three lakes of the current study area (the historical records suggest that $O$. hupensis was absent from the Hongze and Baima lake areas), we were not able to assess neither the sensitivity nor the specificity of our model.

It has been suggested that an early warning system should be set up in China to monitor subtle changes in intermediate host snail habitats due to global warming and other natural or man-made ecological transformations (Zhou et al., 2002b). GIS and remote sensing provide a means to map, predict and monitor disease trends, including the dynamics of vectors and intermediate hosts. In addition, these techniques allow the development of 
models that can be used to predict changes in disease patterns. In this study, we have identified approximately $163.6 \mathrm{~km}^{2}$ of potential new O. hupensis habitats in the vicinity of Hongze, Baima and Gaoyou lakes, which account for $4.3 \%$ of the total snail habitats in China. The generated risk map illustrates the scale of the possible impact of global warming and other ecological transformations on the distribution of O. hupensis, and is useful to inform mitigation policies to avoid the possible spread of intermediate host snails, and hence schistosomiasis japonica.

\section{Acknowledgements}

This work received financial support from the UNICEF/UNDP/World Bank/WHO Special Programme for Research and Training in Tropical Diseases (TDR), project M8/181/4/Y.88 (ID-A10775), the Chinese National Science Foundation (No. 300070684 and No. 30590373) and the Swiss National Science Foundation (P. Vounatsou, project No. 3252B0-102136; J. Utzinger, project No. PP00B102883). We thank Mr. P. Steinmann for a series of helpful comments on an earlier version of this manuscript.

\section{References}

Bian Y, Sun Q, Zhao ZY, Blas E, 2004. Market reform: a challenge to public health - the case of schistosomiasis control in China. Int J Health Plann Manage 19, S79-S94.

Chen MG, Feng Z, 1999. Schistosomiasis control in China. Parasitol Int 48, 11-19.

Crist EP, Cicone RC, 1984. A physically-based transformation of thematic mapper data- the TM tasseled cap. IEEE Trans Geosci Remote Sensing 22, 256-263.

ENVI, 2003. ENVI User's Guide. Research Systems, Inc., Boulder, USA.

Guo JG, Vounatsou P, Cao CL, Utzinger J, Zhu HQ, Anderegg D, Zhu R, He ZY, Li D, Hu F, Chen MG, Tanner M, 2005. A geographic information and remote sensing based model for prediction of Oncomelania bupensis habitats in the Poyang Lake area, China. Acta Trop 96, 213-222.
Haines A, Kovarts RS, Campbell-Lendrun D, Corvalan C, 2006. Climate change and human health: impacts, vulnerability, and mitigation. Lancet 367, 2101-2109.

Hunter PR, 2003. Climate change and waterborne and vectorborne disease. J Appl Microbiol 94 (Suppl), 37S-46S.

IPCC, 2001. Climate change 2001: impacts, adaptation and vulnerability. Cambridge University Press, Cambridge.

Jordan P, 2000. From Katayama to the Dakhla Oasis: the beginning of epidemiology and control of bilharzia. Acta Trop 77, 9-40.

Liang S, Yang CH, Zhong B, Qiu DC, 2006. Re-emerging schistosomiasis in hilly and mountainous areas of Sichuan, China. Bull World Health Organ 84, 139-144.

Lin DD, Zhou XN, Liu Y, Sun L, Hu F, Yang G, Hong Q, 2002. Prediction of snail habitats in the marshland around Poyang Lake affected by flood in 1998 using remote sensing. Chin J Schisto Cont 14, 119-121.

Logan OT, 1905. A case of dysentery in Hunan province caused by the trematode Schistosoma japonicum. China Missionary Medical Journal 19, 243-245.

Maegraith B, 1958. Schistosomiasis in China. Lancet 271, 208-214.

Mao CP, 1948. A review of the epidemiology of schistosomiasis japonica in China. Am J Trop Med Hyg 28, 659-672.

Mao CP, 1990. Biology of Schistosome and Control of Schistosomiasis. People's Health Press, Beijing.

Mao CP, Shao BR, 1982. Schistosomiasis control in the People's Republic of China. Am J Trop Med Hyg 31, 92-99.

McMichael AJ, Woodruff RE, Hales S, 2006. Climate change and human health: present and future risks. Lancet 367, 859-869.

$\mathrm{MOH}, 2000$. Complication of schistosomiasis research 19901999. Ministry of Health, Beijing, China.

Murphy JM, Sexton DM, Barnett DN, Jones GS, Webb MJ, Collins M, Stainforth DA, 2004. Quantification of modelling uncertainties in a large ensemble of climate change simulations. Nature 430, 768-772.

Qi J, Chehbouni A, Huete AR, Keer YH, Sorooshian S, 1994. A modified soil vegetation adjusted index. Remote Sens Environ 48, 119-126.

Ross AGP, Sleigh AC, Li YS, Davis GM, Williams GM, Jiang Z, Feng Z, McManus DP, 2001. Schistosomiasis in the People's Republic of China: prospects and challenges for the 21st century. Clin Microbiol Rev 14, 270-295. 
Sutherst RW, 2004. Global change and human vulnerability to vector-borne diseases. Clin Microbiol Rev 17, 136-173.

Utzinger J, Zhou XN, Chen MG, Bergquist R, 2005. Conquering schistosomiasis in China: the long march. Acta Trop 96, 69-96.

WHO, 2003. Climate Change and Human Health: Risk and Responses. World Health Organization, Geneva.

Yang GJ, Vounatsou P, Zhou XN, Tanner M, Utzinger J, 2005a. A potential impact of climate change and water resource development on the transmission of Schistosoma japonicum in China. Parassitologia 47, 127-134.

Yang GJ, Vounatsou P, Zhou XN, Utzinger J, Tanner M, 2005b. A review of geographic information system and remote sensing with applications to the epidemiology and control of schistosomiasis in China. Acta Trop 96, 117-129.

Zhang ZY, Xu DZ, Zhou XN, Zhou Y, Liu SJ, 2005. Remote sensing and spatial statistical analysis to predict the distri- bution of Oncomelania bupensis in the marshland of China. Acta Trop 96, 205-212.

Zhou XN, Lin DD, Yang HM, Chen HG, Sun LP, Yang GJ, Hong QB, Brown L, Malone JB, 2002a. Use of Landsat TM satellite surveillance data to measure the impact of the 1998 flood on snail intermediate host dispersal in the lower Yangtze River Basin. Acta Trop 82, 199-205.

Zhou XN, Wang LY, Chen MG, Wu XH, Jiang QW, Chen XY, Zheng J, Utzinger J, 2005. The public health significance and control of schistosomiasis in China - then and now. Acta Trop 96, 97-105.

Zhou XN, Wang TP, Wang LY, Guo JG, Yu Q, Xu J, Wang RB, Chen Z, Jia TW, 2004. The current status of schistosomiasis epidemics in China. Chin J Epidemiol 25, 555-558.

Zhou XN, Yang GJ, Sun LP, Hong QB, Yang K, Wang RB, Hua ZH, 2002b. Potential impact of global warming on the transmission of schistosomiasis. Chin J Epidemiol 23, 83-86. 